\title{
Population census of Cook's Petrel Pterodroma cookii breeding on Codfish Island (New Zealand) and the global conservation status of the species
}

\author{
MATT J. RAYNER, KEVIN A. PARKER and MICHAEL J. IMBER
}

\begin{abstract}
Summary
Codfish Island is the southernmost breeding location for Cook's Petrel (Pterodroma cookii), endemic to the New Zealand archipelago. To provide a population estimate and indication of population growth following introduced predator eradications we conducted an island-wide survey of Codfish Island within two a priori defined strata. Plot surveys revealed only five burrows within forest habitats from 175 plots surveyed and the locations of these and other burrows observed incidentally were used to identify three key areas of Cook's Petrel breeding activity that were subsequently surveyed using line transects. Within these areas, 42 burrows were counted with burrow densities ranging from 0.0003 to 0.002 burrows $\mathrm{m}^{-2}$. Burrow densities in conjunction with the three-dimensional surface areas of the surveyed locations suggested a minimum of 6,194 \pm 956 burrows present and equated to approximately 5,000 (95\% CI 3,00o-6,000) breeding pairs, using a burrow occupancy estimate of $80 \%$. The Cook's Petrel population on Codfish Island appears to have increased markedly since Weka (Gallirallis australis ) and Pacific Rat (Rattus exulans) were eradicated in 1980 and 1998 and is consistent with a recent upwards revision of the species' world population size of approximately 1,300,000 (900,000-1,800,000) individuals. Revised population data, and ongoing protection of Cook's Petrel's major breeding sites may now qualify the species for a revised conservation status moving from Endangered to Vulnerable under IUCN criteria.
\end{abstract}

\section{Introduction}

Cook's Petrel (Pterodroma cookii) is a seasonal transequatorial migrant seabird restricted to the Pacific Ocean and breeding only in the New Zealand archipelago during the austral summer (Imber et al. 2003a). Although prehistorically abundant on mainland New Zealand, Cook's Petrel declined following human colonisation as a result of predation by introduced mammals, the destruction of forest breeding habitat and hunting (Holdaway et al. 2001, Worthy and Holdaway 2002). The species is today classified as 'Endangered' under IUCN criteria (BirdLife International 2006) and is restricted to three breeding locations on Little Barrier Island (Hauturu), Great Barrier Island) (Aotea), and Codfish Island (Whenua Hou) (Imber et al. 2003a).

Little Barrier Island (3,00o ha) supports the largest breeding population of Cook's Petrel with 286,000 (213,000-413,000) pairs (Rayner et al. 2007a) breeding annually on forested slopes, predominantly between 300 and $722 \mathrm{~m}$ a.s.l. (Rayner et al. 2007b) Predation by introduced cats (Felis cattus) and Pacific Rat (Kiore; Rattus exulans) had threatened this colony. However, eradications of cats in 1980 and Pacific Rat in 2004 have arrested apparent declines (Imber et al. 2003a, Rayner et al. 2007c). On Great Barrier Island, Cook's Petrels are threatened by cats, dogs (Canis familiaris), rats ( $R$. exulans, $R$. rattus) and pigs (Sus scrofa) with only 12 active burrows being found despite extensive searches over the last 25 years (Scofield 1990, Taylor 2000, Imber et al. 2003a). Codfish Island (1,369 ha) is situated approximately $1,000 \mathrm{~km}$ to the south of Little Barrier Island and Great Barrier Island, rising to a height of $348 \mathrm{~m}$. Cook's Petrels were discovered breeding on Codfish Island in 1934 at which time the population was estimated to be 
occupying 20,000 + burrows in temperate forest over most of the island (Stead 1936). Predation, predominantly by introduced Weka (Gallirallis australis) and possibly Pacific Rat (Imber et al. 2003a), led to the decline of this population to as few as 100 breeding pairs by the early 1980 os (Bartle et al. 1990, Imber et al. 2003a). Whether the eradication of Weka in 1984 and of Pacific Rat in 1998 have resulted in an increase in the size of this Cook's Petrel population is unknown.

There are currently no rigorous population data for Cook's Petrels breeding on Codfish Island. Such data are important, given the limited breeding range of the species and the possibility, given the larger size of Codfish Island birds and asynchronous breeding between northern and southern populations (Imber et al. 2003a), that the two populations may be reproductively isolated. This study sought to provide an accurate assessment of the size of the Cook's Petrel population on Codfish Island, an indication of the recovery of the colony since predator eradications, and a global revision of the conservation status of the species.

\section{Materials and Methods}

\section{Plot Survey}

Field work assessing the size of the Cook's Petrel population on Codfish Island was conducted between 7 and 21 February 2007. There are six species of burrowing seabirds on Codfish Island; Common Diving Petrel (Pelecanoides urinatrix), South Georgian Diving Petrel (P. georgicus), Broad-billed Prion (Pachyptila vittata), Cook's Petrel, Mottled Petrel (Pterodroma inexpectata) and Sooty Shearwater (Puffinus griseus). Diving petrels and prions are restricted to sand dunes and areas near the coast, but there is potential for habitat overlap among the remaining three species (pers. obs.). Cook's Petrel is a forest nesting species (Imber et al. 2003a, Rayner et al. $2007 \mathrm{~b}$ ) and on Codfish Island is potentially excluded from coastal scrub habitats by large breeding populations of Mottled Petrel and Sooty Shearwater. As a result, two habitat strata were selected a priori for our survey: forest and low scrub/coastal habitats. A vegetation map of Codfish Island within a Geographic Information System (GIS) was then used to partition each stratum. A GIS-based digital elevation model of Codfish Island was used to calculate the surface area of each stratum and apportion survey effort. Forest habitats were 1,066 ha in area, approximately twice as large as the scrub/coastal cliff habitats (531 ha); therefore 150 sites were selected within forest habitats and 75 within shrub/coastal cliff habitats. Survey locations were then generated from random coordinates within a GIS. During the survey, observers navigated to the coordinates of each survey site using a handheld Global Positioning System (GPS). Where the exact coordinates could not be reached, due to GPS inaccuracy, a random compass bearing was taken from the current location and a handheld field tape run out over the error distance registered by the GPS to establish the centre of the survey location. At each survey site a $6 \mathrm{~m}$ diameter $\left(28.26 \mathrm{~m}^{2}\right)$ plot was established with one worker standing in the centre of the plot with the field tape extended to a $3 \mathrm{~m}$ radius. The second worker used the tape to search for and record all petrel burrows within the plot.

\section{Burrow selection}

Burrows were recorded when greater than $0.5 \mathrm{~m}$ in length (measured by arm or with a stick) and considered to have been in active use by petrels within one or two breeding seasons with signs such as excavated soil, scratch marks, or guano (Rayner et al. 2007b). Given the potential presence of a number of burrowing species within the habitat surveyed and that Cook's Petrel is the smallest species present (Cook's Petrel $200 \mathrm{~g}$ (Imber et al. 2003a); Mottled Petrel $329 \mathrm{~g}$ (Warham et al. 1977) ; Sooty Shearwater 819 g (Warham et al. 1982)), each burrow recorded had its internal width and height measured $300 \mathrm{~mm}$ inside the burrow entrance. To provide a decision rule for assigning burrow status, width and height measurements were also made from burrows at known Cook's Petrel and Mottled Petrel burrows (within established study sites, 
Fig. 1), the two species most similar in size and whose burrows were most likely to be confused. Burrow dimensions between these species were compared using chi-square analyses, and as a result of consistent and significant differences, burrows measured in the field that fell within the $95 \%$ confidence intervals for measurements from known Cook's Petrel burrows were considered to be occupied by Cook' s Petrel.

Plot surveys were conducted during 7-14 February and 179 sites were surveyed (149 within the forest stratum and 35 within the shrub/coastal cliff habitats) with only five Cook's Petrel burrows being recorded in five separate plots within the forest stratum. Given that Cook's Petrel burrows were being observed and marked with GPS coordinates by workers in transit between survey sites in the forest stratum, and that high densities of Mottled Petrel and Sooty Shearwater burrows were being recorded in the shrub/coastal cliff stratum, without a single observation of a Cook's Petrel burrow in this stratum, it was decided to focus remaining survey efforts within only the forest stratum.

\section{Transect survey}

Similar locations for (i) Cook's Petrel burrows recorded during our initial plot survey, (ii) incidental observations of burrows recorded and GPS marked outside plots during the island-wide survey, and (iii) long-term Cook's Petrel study burrows, enabled identification of

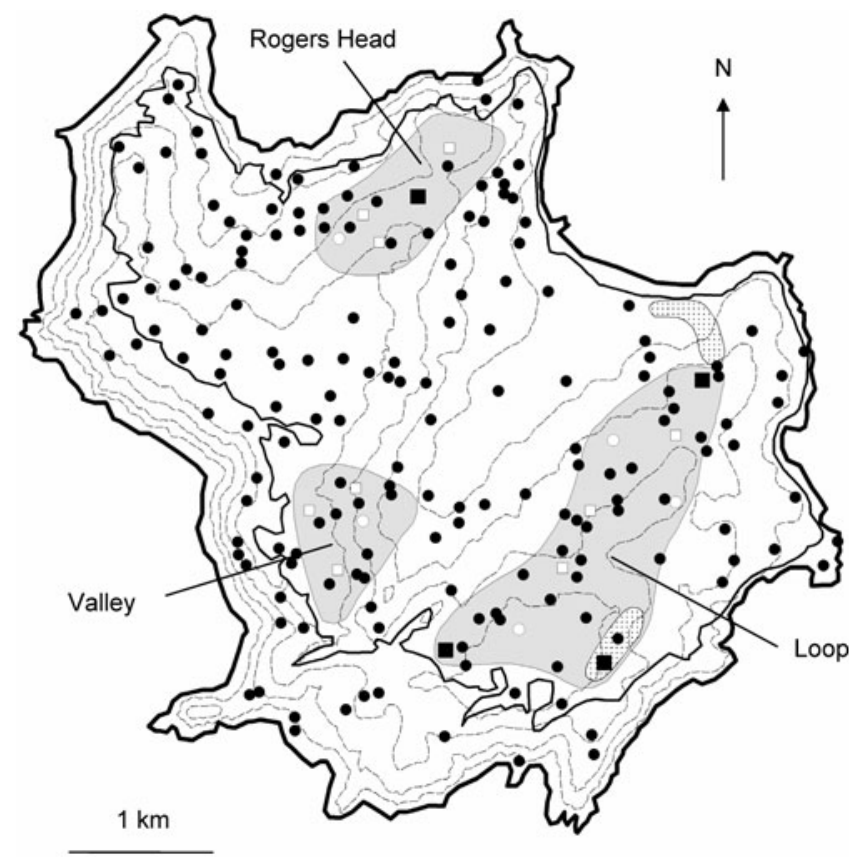

Figure 1. Map of Codfish Island, showing $50 \mathrm{~m}$ altitude contours (dashed lines), forest strata (within light black line) and low scrub/coastline strata (outside of light black line and within coastline). Black circles represent Cook's Petrel burrow survey plots, white circles circular plots where single Cook's Petrel burrows were present. White squares represent the location of Cook's Petrel burrows observed outside of plots during fieldwork, black squares locations of long-term Cook's Petrel monitoring grids, dotted areas locations of high (southern-most area) and lowaltitude (northern-most area) study burrows, and grey shaded areas locations within which transect surveys were conducted. 
three main areas for further surveying of what appeared to be a spatially discontinuous distribution of Cook's Petrel within the forest stratum. These areas, named Loop, Valley and Rogers Head, were drawn on a topographic map of the island and best encompassed the observed locations of Cook's Petrel burrows within them. The approximate two-dimensional area of each, calculated from the map, was used to apportion survey effort within each area (these areas were later entered into a GIS and the three-dimensional surface area of each calculated).

Each of the three areas was sampled using $50 \mathrm{~m}$ line transects. Within the Loop and Rogers Head areas the available track system was used as a baseline from which to conduct sampling. Within the Valley area, a lack of tracks meant a compass bearing was followed down the centre of the area, and sampling conducted off the sides of this bearing. At $200 \mathrm{~m}$ intervals along the track system, or compass baseline, we randomly selected and paced a distance of o, 50, 100 or 150 or $200 \mathrm{~m}$ perpendicular to the baseline using a handheld compass. A $50 \mathrm{~m}$ transect was then established at the location using a field tape placed across the predominant gradient, thereby including ridges, slopes and valleys. Each field worker then walked from opposite ends of the transect, counting burrows present within $2 \mathrm{~m}$ on each side of the transect (thus surveying 200 $\mathrm{m}^{2}$ ) and using the same burrow selection protocols as for the plot survey. The strip transect method $D=n / 2 w L$, after Buckland et al. (2001), was used to estimate the density of Cook's Petrel burrows within each area where $D=$ estimated density, $n=$ number of detections, $w=$ width either side of the centreline and $L=$ total length.

\section{Burrow occupancy}

The proportion of burrows occupied by breeding Cook's Petrels was estimated through inspection of 43 established study burrows in a low-altitude study colony (Fig. 1) during this survey, and from inspections of the same site and a high-altitude site (10 burrows) (Fig. I) in March 2006. Study burrows had previously had a hole excavated to the breeding chamber and been sealed with a flat rock (Imber et al. 2003a). Each burrow was opened and inspected for the presence of a Cook's Petrel chick. Petrel burrow occupancy is traditionally considered to be the proportion of burrows in which an egg is laid, with egg loss, infertility and chick death potential sources of bias to occupancy measured halfway through the breeding season (Imber et al. 2003 b). On Little Barrier Island 10\% of breeding attempts over three breeding seasons (2004-2007) failed due to egg infertility or chick death (pers. obs.) and the occupancy measure (number of chicks present in burrows) was scaled upwards by this amount to account for these factors.

\section{Results}

Measurements of known Cook's $(n=20)$ and Mottled Petrel $(n=38)$ study burrows at established study sites were significantly different in height $\left(\chi^{2}{ }_{1}=22.93, P<0.001\right)$ and width $\left(\chi_{1}^{2}=21.98, P<\right.$ o.001) (Fig. 2$)$ and we were thus confident in being able to select only Cook's Petrel burrows using during our survey using burrow selection protocols (see methods).

Fig. I shows the locations of stratum boundaries and plots surveyed during the island-wide survey, the five plots where individual Cook's Petrel burrows were observed, the locations of established study burrows and the boundaries of the Loop, Valley and Rogers Head areas where transect surveying was conducted. Burrow densities within transect surveyed areas were highest in the Rogers Head area with 28 transects surveyed and 16 burrows recorded for a burrow density of $0.003 \pm 0.0002$ burrows $\mathrm{m}^{-2}$ (Table 1 ). Within the Loop area 56 transects were surveyed and 25 burrows counted with an average burrow density of $0.002 \pm 0.0003$ burrows $\mathrm{m}^{-2}$ (Table 1 ). Within the Valley area one burrow was recorded from 18 transects surveyed for a burrow density of 0.0003 burrows $\mathrm{m}^{-2}$ (Table 1 ). 


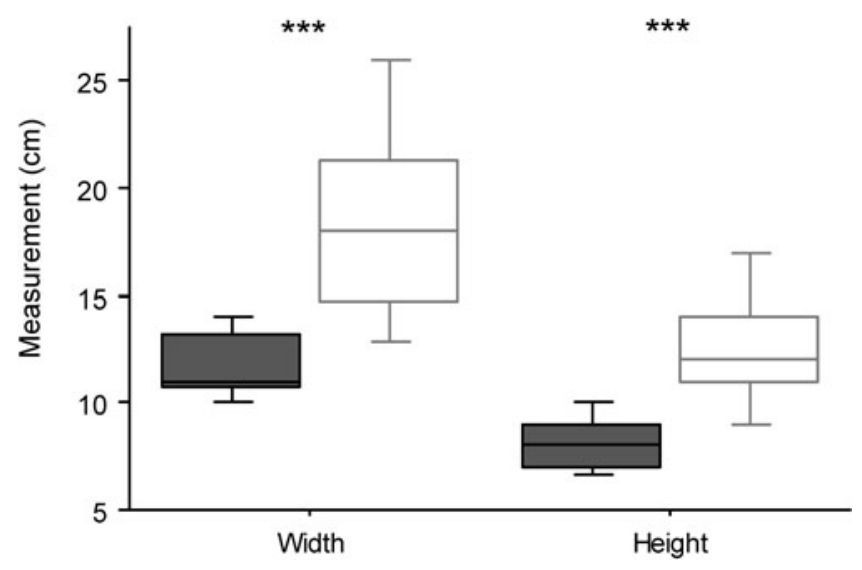

Figure 2. Box plots of dimensions of known Cook's Petrel $(n=20)$ (grey boxes) and Mottled Petrel $(n=38)$ (white boxes) burrows. Centre line of box represents median, boxes interquartile ranges and bars minimum and maximum values. ${ }^{* *} P<0.001$.

Table 1. Transects surveyed for Cook's Petrel burrows on Codfish Island showing surface area, burrow density $\mathrm{m}^{-2}$, the estimated number of burrows within each area and total burrow counts and area.

\begin{tabular}{lclc}
\hline Survey area & Area $(\mathrm{Ha})$ & Density $\left(\mathrm{m}^{-2}\right)$ & Burrows $(\mathrm{n} \pm \mathrm{SE})$ \\
\hline Loop & 160.9 & 0.002 & $3,591 \pm 642$ \\
Rogers Head & 65.0 & 0.003 & $2,460 \pm 412$ \\
Valley & 51.5 & 0.0003 & $143 \pm 147$ \\
Total & & $6,194 \pm 956$ \\
\hline
\end{tabular}

The percentage of Cook's Petrel burrows occupied by a chick in the 2006 and 2007 seasons averaged $73 \%$. At the low-altitude study site in the 2007 season occupancy was $70 \%$ (30 chicks from 43 burrows) whilst in the 2006 season occupancy was $75 \%$ ( 32 chicks from 43 burrows) at the low-altitude study site, and 80\% (8 chicks from 1o burrows) at the high-altitude study site. Allowing $10 \%$ for infertility and breeding failures equates to an occupancy rate of $80 \%(77$ chicks from 96 burrows over two seasons) which was used to scale area-based population estimates.

The three-dimensional areas of the three transect-surveyed areas and estimated burrow numbers, totalling 6,194 \pm 956 burrows, are shown by Table 1 . Using a burrow occupancy value of $80 \%$ suggests that in the 2007 breeding season Codfish Island held a minimum of 4,956 $(3,415-6,497)$ breeding pairs of Cook's Petrel.

\section{Discussion}

Low burrow densities and patchy distribution of Cook's Petrel burrows made selection of the best method for quantifying the Codfish Island population size difficult, with the low detection rate of burrows precluding more complex predictive analyses (Rayner et al. 2007a). The extrapolation of burrow densities across large areas of predefined habitat can result in biased estimates for seabird populations with spatially discontinuous distributions (Rayner et al. 2007a). Our method of calculating estimates within focused areas of known Cook's Petrel presence was thus appropriate for obtaining a reliable minimum estimate of Cook's Petrel 
population size. However confidence interval estimates may be unreliable given the small number of burrows counted ( 42 in total).

The results of this study suggest the Cook's Petrel population on Codfish Island is a minimum of approximately 5,000 breeding pairs, with an unknown number of burrows outside areas surveyed to establish this estimate. Apart from four locations where Cook's Petrel study burrows and monitoring grids were established from 1982 (Imber et al. 2003a), (Fig. I) numerous searches of Codfish Island for Cook's Petrel burrows between 1975 and 1995 had revealed only 4 additional burrows prior to this survey (pers. obs.). These included one near the island's summit in the Rogers Head area, and three scattered burrows on the western flank of the Loop area. Today, burrows are scattered across large areas of slope and ridge-top habitat predominantly at higher altitudes with burrow densities an order of magnitude less than those of the Cook's Petrel colony on Little Barrier Island (0.04 burrows $\mathrm{m}^{-2}$ ) (Rayner et al. 2007b). Ridge-top habitats utilised in Codfish Island are similar to those used on Little Barrier Island and likely provide birds with easier access through the forest canopy and free-draining soils for burrowing (Rayner et al. 2007b).

Comparison between our survey data and historic anecdotal observations of the distribution of Cook's Petrel breeding on Codfish Island suggest that the population may have increased several times since the eradication of Weka in 1984. This increase may also have accelerated in the nine years since Pacific Rat eradication (Imber et al. 2003a). Scaling our estimate of the Cook's Petrel population breeding population by a breeder-to pre-breeder ratio of 0.5 , and allowing 0.1 to account for non-breeding individuals in the population (Rayner et al. 2007a) suggests a minimum total population for Codfish Island of $10,000(7,000-14,000)$ individuals. This result is consistent with that of Rayner et al. (2007a) who propose a world-wide population for Cook's Petrel of $1,300,000$ individuals, of which the Codfish Island population makes up approximately $2 \%$.

Cook's Petrel is classified as 'Endangered' under IUCN criterion Bzab (i, ii, iv) (BirdLife International 2006). This classification is based upon the species' restriction to no more than five locations (B2a), the continuing decline of the species' extent of occurrence, area of occupancy and number of locations or subpopulations (B2 $\mathrm{i}$, ii, iv) and thus very high risk of extinction in the wild (BirdLife International 2006). Currently Cook's Petrel is listed as occupying three breeding locations: Little Barrier Island, Codfish Island and Great Barrier Island. Recent studies of the Little Barrier Island (Rayner et al. 2007a) and Codfish Island (this study) Cook's Petrel populations have made significant revisions to the world population for this species. In addition, breeding data collected after the eradication of the last introduced predator from Codfish Island (Pacific Rat, 1999) (Imber et al. 2003a) and Little Barrier Island (Pacific Rat, 2004) (unpubl. data) suggest a recovery of these populations following management actions. Population estimate revisions, and the recovery of the Little Barrier Island and Codfish Island populations, leave the Great Barrier Island Cook's Petrel population as the sole basis for the species B2 b (continuing decline) classification. However, it appears that Cook's Petrel may have been effectively extinct as a reproductively viable population on Great Barrier Island for several decades (Scofield 1990, Taylor 2000, Imber et al. 2003a) with its continued presence possible only as a result of the location's close proximity to, and recruitment from, the large colony on Little Barrier Island. Continuing threats from introduced predators are unlikely to allow reestablishment of the species on Great Barrier Island. The greatest threat to the Codfish Island and Little Barrier Island populations would be invasion of these islands by introduced predators. Given that these islands are widely separated, and managed intensively by the New Zealand Department of Conservation, it is unlikely that the Cook's Petrel faces a high risk of extinction in the wild under $B_{2}$ criteria despite being restricted to two breeding locations. Accordingly the species likely qualifies as 'Vulnerable' by not fully qualifying for the B2 criterion. In the event that the conservation status of this species is reassigned, monitoring programmes, in place for these populations, would allow for rapid assessment of new threats and appropriate conservation actions to occur. 


\section{Acknowledgments}

Pete McClellend provided much appreciated logistical support throughout this project and Ros Cole, Schannel van Dijken, Don Geddes, John Henderson, Peter Howden and Paul Jacques kindly assisted with field work. Tristan Rawlance and Deidre Vercoe, National Kakapo Team, facilitated our stay on Codfish Island and the Department of Conservation, Southern Islands Conservancy and the Whenua Hou Committee kindly provided access to Codfish Island. We thank Mark Hauber and an anonymous referee for improving the quality of the manuscript. M.J.R was supported by New Zealand Tertiary Education Commission Bright Futures Doctoral Scholarship.

\section{References}

Bartle, J. A., Hu, D., Stahl, J. C., Pyle, P., Simons, T. R. and Woodby, D. (1990) Status and ecology of gadfly petrels in the temperate north pacific. Proceedings of an International Symposium of the Pacific Seabird Group, Canadian Wildlife Service, and the British Columbia Ministry of Environment, Lands and Parks. Victoria, British Columbia, Publications Division, Canadian Wildlife Service, Ontario, Canada.

Buckland, S. T., Anderson, D. R., Burnham, K. P., Laake, J. L., Borchers, D. L. and Thomas, L. (2001) Introduction to distance sampling. Oxford, UK: Oxford University Press.

Holdaway, R. N., Worthy, T. H. and Tennyson, A. J. D. (2001) A working list of breeding bird species of the New Zealand region at first human contact. New Zealand J. Zool. 28: 119-187.

Imber, M. J., West, J. A. and Cooper, W. J. (2003) Cook's petrel (Pterodroma cookii): historic distribution, breeding biology, and effects of predators. Notornis 50: 221-230.

Imber, M. J., Wood, S. E. and Cotter, R. N. $(2003 \mathrm{~b})$ An estimate of the number of grey-faced petrels (Pterodroma macroptera gouldi) breeding on Moutohora (Whale Island), Bay of Plenty, New Zealand, during 1998-2000. Notornis 50: 23-26.

Birdlife International (2006) Pterodroma cookii. In: IUCN 2006. 2006 IUCN Red List of threatened species. <www.iucnredlist.org $>$ (Downloaded on o8 July 2007).

Rayner, M. J., Clout, M. N., Stamp, R. K., Imber, M. J., Brunton, D. H. and Hauber, M. E. (2007a) Predictive habitat modelling improves the population census accuracy of a burrowing seabird: a study of the endangered Cook's petrel. Biol. Conserv. 138: 235-247.

Rayner, M. J., Hauber, M. E. and Clout, M. N. (2007b) Breeding habitat of the Cook's Petrel (Pterodroma cookii) on Little Barrier Island (Hauturu): implications for the conservation of a New Zealand endemic. Emu 107: 59-68.

Rayner, M. J., Hauber, M. E., Imber, M. J., Stamp, R. K. and Clout, M. N. (2007c) Spatial heterogeneity of mesopredator release within an oceanic island system. Proc. Natl. Acad. Sci. USA.

Scofield, P. (1990) The status of Cook's petrel on Great Barrier Island. Notornis 37: 130.

Stead, E. F. (1936) A new nesting site of Cook's petrel Pterodroma cookii. Trans. R. Soc. New Zealand 66: 315.

Taylor, G. A. (2000) Action plan for seabird conservation in New Zealand, part a: threatened seabirds. Wellington, NZ: New Zealand Department of Conservation Threatened Species Occasional Publication 16.

Warham, J., Keeley, B. R. and Wilson, B. A. (1982) The size of the sooty shearwater population at the Snares Islands, New Zealand. Notornis 29: 23-30.

Warham, J., Keeley, B. R. and Wilson, G. J. (1977) Breeding of the mottled petrel. Auk 94: 1-17.

Worthy, T. H. and Holdaway, R. N. (2002) The lost world of the moa: prehistoric life of New Zealand. Christchurch: Canterbury University Press. 
MATT J. RAYNER*

School of Biological Sciences, The University of Auckland, Private Bag 92019, Auckland, New Zealand.

\section{KEVIN A. PARKER}

Institute of Natural Resources, Massey University, Private Bag 102904, North Shore Mail Centre, Auckland, New Zealand.

MICHAEL J. IMBER

6 Hillcrest Lane, Levin 5500, New Zealand.

*Author for correspondance; e-mail:m.rayner@auckland.ac.nz

Received 9 July 2007; revision accepted 3 December 2007 